\title{
COVID-19 Management: What We Need to Know?
}

\section{Introduction}

The world is plagued by the COVID-19 pandemic. This is an unprecedented situation in the modern era wherein we do not know our enemy in detail. In fact, we hardly know anything. We have just started to learn about COVID-19; the management guidelines are evolving and are mostly consensus based at present, rather than randomized data. In this article, we will briefly review some important updates and evolving research in the management of COVID-19.

\section{Testing}

\section{Diagnostic testing}

Nasopharyngeal swab by real-time reverse transcriptionpolymerase chain reaction (rRT-PCR) is the recommended testing method for COVID-19. ${ }^{[1]}$ RT-PCR has a high specificity and does not cross-react with other human coronaviruses and respiratory pathogens. ${ }^{[2]}$

Antibody-based rapid testing in the blood is not recommended by the World Health Organization as results are dependent on age, nutritional status, the severity of illness, concurrent medications, and immunosuppression like human immunodeficiency virus (HIV).

\section{Indications for testing (Indian Council of Medical Research Guidelines)}

1. All symptomatic individuals who have undertaken international travel in the past 14 days

2. All symptomatic contacts of laboratory COVID-19 confirmed cases

3. All symptomatic health-care workers

4. All patients with severe acute respiratory illness (fever and cough and/or shortness of breath)

5. Asymptomatic direct and high-risk contacts of a confirmed case should be tested once between day 5 and day 14 of coming in his/her contact

6. All symptomatic influenza-like illness with fever, cough, sore throat, and/or runny nose (in hotspots/cluster and large migration gatherings/evacuees canters):

a. Within 7 days of illness - rRT-PCR

b. After 7 days of illness - Antibody test (if negative, confirmed by rRT-PCR). ${ }^{[3]}$

\section{Treatment}

The current standard of care for COVID-19 infection is symptomatic supportive care. The potential investigational therapies include antivirals, antibodies, cell-based therapy, ribonucleic acid (RNA)-based therapy, and others. Surviving sepsis management guidelines in mentioned in Table 1.

\section{Investigational therapies}

Remdesivir

Remdesivir, a nucleotide analog prodrug that inhibits viral RNA polymerases and has shown in vitro activity against severe acute respiratory syndrome coronavirus $2 .{ }^{[4]}$

In a study of 53 patients with severe COVID-19 (oxygen saturation of $<94 \%$ in room air or who receiving oxygen support), the patients received remdesivir on a compassionate basis for 10 days (200 mg intravenously on day 1 , followed by $100 \mathrm{mg}$ daily for 9 days). At baseline, $57 \%$ patients received mechanical ventilation and $8 \%$ received extracorporeal membrane oxygenation. This study showed that $68 \%$ had an improvement in oxygen support, $57 \%$ of ventilated patients were extubated, $47 \%$ discharged, and $13 \%$ died. The limitations of this study are small numbers, short duration of follow-up (18 days), nonrandomized design, late initiation of treatment (remdesivir was started 12 days from the start of symptoms), different duration of remdesivir treatment, and no data on viral load. ${ }^{[5]}$

\section{Lopinavir-Ritonavir}

Lopinavir/ritonavir combination showed in vitro activity against other novel coronaviruses through inhibition of 3-chymotrypsin-like protease. ${ }^{[4]}$ It is Food and Drug Administration (FDA) approved for the treatment for HIV.

A randomized controlled, open-label trial was done in adult hospitalized Chinese patients with severe COVID-19 (oxygen saturation of $<94 \%$ in room air or a ratio of the partial pressure of oxygen to the fraction of inspired oxygen of $<300 \mathrm{mmHg}$ ). Patients were randomly assigned in a 1:1 ratio to receive either lopinavirritonavir (400 mg and $100 \mathrm{mg}$, respectively) twice a day for 14 days, in addition to standard care, or standard care alone. A total of 199 patients were randomized, and mortality at 28 days was similar in the lopinavir-ritonavir group and the standard care group $(19.2 \%$ vs. $25.0 \%$; difference: $-5.8 \%$ points; $95 \%$ confidence interval [CI]: $-17.3-5.7)$. This study showed that there was no benefit (clinical improvement, reduction in mortality, or reduction in viral RNA load) when treated with antiviral drugs (lopinavirritonavir combination) as compared to standard of care treatment. ${ }^{[6]}$ Currently, this is the only published phase 3 randomized controlled trial (RCT) for the management of COVID-19 infection.

\section{Hydroxychloroquine/chloroquine and azithromycin}

Chloroquine and hydroxychloroquine are used in the treatment of malaria, discoid/systemic lupus erythematosus, and rheumatoid arthritis. These drugs 
Table 1: Surviving sepsis guidelines: management of critically ill adults with COVID-19[19]

Recommendation

Health-care workers performing aerosol-generating procedures should use N95 respirators in addition to other personal protective equipment (gloves, gown, and face shield/goggles) in a negative pressure room

The most experienced person with airway management should intubate and use video-guided laryngoscopy (if available) to minimize the number of attempts and risk of transmission

Supplemental oxygen should be started if the peripheral $\mathrm{SPO}_{2}$ is $<92 \%$

For patients with acute hypoxemic respiratory failure on oxygen, $\mathrm{SpO}_{2}$ be maintained not higher than $96 \%$

For patients with hypoxemia despite conventional oxygen, HFNC/NIPPV can be used with close monitoring of the respiratory status. If worsening is suspected, early intubation in a controlled environment is advised

For intubated patients with suspicion of COVID-19 infection, the endotracheal aspirate is the preferred specimen for COVID-19 testing

In mechanically ventilated patients with ARDS, low tidal volume ventilation (4-8 $\mathrm{mL} / \mathrm{kg}$ of predicted body weight) and targeting plateau pressures of $<30 \mathrm{~cm} \mathrm{H}_{2} \mathrm{O}$

For patients with moderate-to-severe ARDS, target a higher PEEP $>10 \mathrm{~cm} \mathrm{H}_{2} 0$ with monitoring for barotrauma

For patients with moderate-to-severe ARDS, prone ventilation for 12-16 h with judicious use of neuromuscular blocking agents (intermittent bolus or continuous infusion) can be done

For patients with refractory hypoxemia, venovenous ECMO can be done

For mechanically ventilated patients with ARDS, systemic corticosteroid

(methylprednisolone 1-2 mg/kg/day for 5-7 days) can be used

In mechanically ventilated patients with respiratory failure, empiric antibacterial agents can be used

For patients with shock, initial resuscitation should be a conservative fluid strategy with a buffered/balanced crystalloid solution. Avoid starches, dextrans, gelatins, and albumin

For patients with shock, norepinephrine is the preferred first-line vasoactive agent and vasopressin the second-line agent

For patients with cardiogenic shock, dobutamine is the preferred first-line vasoactive agent

For patients with shock on vasopressor support, a MAP of $60-65 \mathrm{mmHg}$ should be targeted

For critically ill patients, paracetamol can be used to control fever

For critically ill patients, treatment options including lopinavir/ritonavir, convalescent plasma, immunoglobulins, interferons, chloroquine/hydroxychloroquine, and tocilizumab are not recommended ${ }^{[19]}$

MAP: Mean arterial pressure, $\mathrm{SPO}_{2}$ : Oxygen saturation, ARDS: Acute respiratory distress syndrome, PEEP: Positive end-expiratory pressure, ECMO: Extracorporeal membrane oxygenation, HFNC: High-flow nasal cannula, NIPPV: Noninvasive positive-pressure ventilation

have immunomodulatory effects and block the viral entry into cells by inhibiting glycosylation of host receptors, proteolytic processing, and endosomal acidification. ${ }^{[4]}$

A French study included twenty patients with COVID-19 infection who were treated with oral hydroxychloroquine sulfate $200 \mathrm{mg}, 3$ times/day with or without azithromycin for 10 days and were compared to controls. There was a reduction in viral loads on day 6 as compared to the controls. The limitations of this study are small sample size, nonrandomized design, and mortality not being the endpoint..$^{[7]}$ Another French study with 11 patients with severe COVID-19 infection treated with hydroxychloroquine $(600 \mathrm{mg} / \mathrm{day}$ for 10 days) and azithromycin (500 mg on day 1 and $250 \mathrm{mg}$ from day 2 to day 5) showed no evidence of rapid antiviral clearance or clinical benefit. ${ }^{[8]}$ Moreover, severe side effects of chloroquine can include psychiatric manifestations, arrhythmias, and sudden death. ${ }^{[9]}$

\section{Inhalational plasminogen therapy}

Plasminogen is a key regulator in fibrin degradation, wound healing, and infection. ${ }^{[10]}$

A study from China with 13 patients who had moderate-tosevere COVID-19 infection were treated with atomization inhalation of free-dried plasminogen $(10 \mathrm{mg}$ OD for moderate and $10 \mathrm{mg} \mathrm{BD}$ for severe infection). Six patients with severe infection had improvement in oxygen saturation, five patients with moderate infection had radiological improvement of pneumonia, and two critical patients with hypoxemia had improvement in saturation within an hour. ${ }^{[10]}$ The limitations of this study are the small sample size, nonrandomized design, and mortality not being evaluated as an endpoint.

\section{Convalescent plasma therapy}

Passive immunization for the treatment of human infectious diseases can be traced back to the $20^{\text {th }}$ century when antibodies were used from the serum of stimulated animals, especially rabbits and horses. ${ }^{[1]}$

A study has been reported from China, in which ten patients who had severe COVID-19 infection received one dose of $200 \mathrm{~mL}$ of convalescent plasma (CP) derived from recently recovered donors with the neutralizing antibody titers above $1: 640$ in addition to supportive care, antiviral agents, and steroids. The clinical symptoms were significantly improved along with an increase in oxygen saturation within 3 days. 
Table 2: Ongoing phase 3 clinical trials

\begin{tabular}{|c|c|c|c|}
\hline Type & Mechanism & Developer/researcher & Sample size \\
\hline Sarilumab & Interleukin-6 antagonist & Sanofi/Regeneron & 400 \\
\hline Remdesivir & Antiviral & \multirow[t]{2}{*}{ Gilead } & 2400 \\
\hline $\mathrm{CD} 24 \mathrm{Fc}$ & Nonviral immunomodulator & & 230 \\
\hline Tocilizumab & $\begin{array}{l}\text { Humanized anti-interleukin- } 6 \text { receptor } \\
\text { monoclonal antibody }\end{array}$ & Roche & 330 \\
\hline Chloroquine/ & Antimalarial & \multirow{2}{*}{$\begin{array}{l}\text { Washington University School of } \\
\text { Medicine }\end{array}$} & \multirow[t]{2}{*}{55000} \\
\hline Hydroxychloroquine & Antirheumatic & & \\
\hline BCG vaccine & Antituberculosis & $\begin{array}{l}\text { Murdoch Children's Research } \\
\text { Institute }\end{array}$ & 4170 \\
\hline Enoxaparin & Anticoagulant & University hospital, Geneva & 200 \\
\hline \multirow{2}{*}{$\begin{array}{l}\text { Hydroxychloroquine/oseltamivir/ } \\
\text { azithromycin }\end{array}$} & Antirheumatic & \multirow[t]{2}{*}{ Shehnoor Azhar, Lahore } & \multirow[t]{2}{*}{500} \\
\hline & Antiviral against $\mathrm{H} 1 \mathrm{~N} 1$ & & \\
\hline $\begin{array}{l}\text { Anakinra, Siltuximab, } \\
\text { Tocilizumab }\end{array}$ & $\begin{array}{l}\text { Antibiotic } \\
\text { Anti-interleukin }\end{array}$ & University hospital, Ghent & 342 \\
\hline Hyperbaric oxygen & Free radical & Karolinska University Hospital & 200 \\
\hline Colchicine & Inhibits microtubules & Montreal Heart Institute & 6000 \\
\hline Naproxen & Anti-inflammatory & $\begin{array}{l}\text { Assistance Publique - Hôpitaux de } \\
\text { Paris }\end{array}$ & 584 \\
\hline Hydroxychloroquine & Antirheumatic & \multirow{2}{*}{$\begin{array}{l}\text { Centre Hospitalier Universitaire de } \\
\text { Saint Etienne }\end{array}$} & \multirow[t]{2}{*}{1200} \\
\hline Ritonavir/lopinavir & Antiviral & & \\
\hline Darunavir/cobicistat + & Antiretroviral & \multirow[t]{2}{*}{ Fundacio Lluita Contra la Sida } & \multirow[t]{2}{*}{3040} \\
\hline chloroquine & Antimalarial & & \\
\hline Nitazoxanide & Antiprotozoal & Romark & 330 \\
\hline Natural honey & Anti-inflammatory, Immunomodulatory & $\begin{array}{l}\text { Misr University for Science and } \\
\text { Technology }\end{array}$ & 1000 \\
\hline Convalescent plasma & Artificially acquired passive immunization & \multirow[t]{4}{*}{ Thomas Benfield } & \multirow[t]{4}{*}{1500} \\
\hline Sarilumab & Interleukin-6 antagonist & & \\
\hline Baricitinib & Janus kinase inhibitor & & \\
\hline Hydroxychloroquine & Antirheumatic & & \\
\hline Cholecalciferol & Vitamin D3 & University hospital, Angers & 260 \\
\hline Pyridostigmine bromide & Acetylcholinesterase inhibitor & Salvador Zubiran & 436 \\
\hline
\end{tabular}

\section{Table 3: Anticancer clinical trials for COVID-19 infection}

\begin{tabular}{lllc}
\hline Type & Mechanism & Developer/researcher & Sample size \\
\hline Bevacizumab & Vascular endothelial growth factor antagonist & Qilu Hospital of Shandong University & 140 \\
Imatinib & Tyrosine kinase inhibitor & Hospital Universitario de Fuenlabrada & 165 \\
\hline
\end{tabular}

Radiological examinations showed varying degrees of resolution of lung lesions within 7 days. The viral load was undetectable after transfusion in seven patients who had previous viremia. The limitations of this study are a small number, nonrandomized design, confounding use of antiviral therapy and steroids, and nonassessment of cytokine changes. This study also does not answer the question of an optimal concentration of neutralizing antibodies and treatment schedule. ${ }^{[12]}$ In another uncontrolled case series of five critically ill patients with COVID-19 and acute respiratory distress syndrome (ARDS) from China, the administration of $\mathrm{CP}$ containing neutralizing antibody was followed by an improvement in clinical status. ${ }^{[13]}$
The Indian Council of Medical Research (ICMR) is planning to do a randomized controlled, open-label trial of $\mathrm{CP}$ therapy versus conventional therapy in COVID-19-infected patients. ${ }^{[14]}$

\section{Tocilizumab}

Tocilizumab is a novel monoclonal antibody that competitively inhibits the binding of interleukin-6 (IL-6) to its receptor. It is FDA approved for the treatment of rheumatoid arthritis and cytokine release syndrome. ${ }^{[4]}$

A study from China reported 15 moderate-to-seriously ill COVID-19-infected patients treated with injection tocilizumab (80-600 $\mathrm{mg})$ with or without 
methylprednisolone. This study showed a reduction of C-reactive protein and IL-6 in patients who received tocilizumab. The limitations of this study are small sample size, nonrandomized design, and again, mortality was not an endpoint. ${ }^{[15]}$

\section{Methylprednisolone}

A retrospective cohort study from China evaluated 201 COVID-19-infected patients with ARDS who were treated with methylprednisolone and reported a lower risk of death (hazard ratio: 0.38 ; 95\% CI: $0.20-0.72$ ). ${ }^{[16]}$ The Chinese thoracic society recommends methylprednisolone $0.5-1 \mathrm{mg} / \mathrm{kg}$ for $<7$ days in selected patients after assessing the risks and benefits. ${ }^{[17]}$ The limitations include the retrospective study design and the potential adverse effects of steroids.

\section{Low-molecular-weight heparin}

A study from China evaluated the use of low-molecular-weight heparin in patients with severe COVID-19. This study enrolled 449 patients, and among them, 99 patients received heparin for 7 or more days. There was no difference in mortality between patients who used heparin and those who did not $(30.3 \%$ vs. $29.7 \%, P=0.910)$. However, the mortality was reduced in patients who used heparin with sepsis-induced coagulopathy score $>4(40.0 \%$ vs. $64.2 \%, P=0.029)$ or D-dimer $>6$-fold of upper limit of normal $(32.8 \%$ vs. $52.4 \%, P=0.017) .{ }^{[18]}$ The limitations of this study are retrospective design and the influence of confounding variables (other therapies).

\section{Infectious Disease Society of America Guidelines}

The Infectious Disease Society of America does not recommend the use of hydroxychloroquine/ chloroquine \pm azithromycin, lopinavir/ritonavir, corticosteroids, tocilizumab, and $\mathrm{CP}$ as a treatment for COVID-19 infection outside the context of a clinical trial.

\section{Prophylaxis (Indian Council of Medical Research National taskforce recommendation)}

1. Asymptomatic health-care workers involved in the care of suspected or confirmed cases of COVID-19: tablet hydroxychloroquine $400 \mathrm{mg}$ twice a day on day 1 , followed by $400 \mathrm{mg}$ once weekly for the next 7 weeks

2. Asymptomatic household contacts of laboratory-confirmed cases:

tablet hydroxychloroquine $400 \mathrm{mg}$ twice a day on day 1 , followed by $400 \mathrm{mg}$ once weekly for the next 3 weeks $^{[20]}$

\section{Contraindications}

Hydroxychloroquine is contraindicated in children below 6 years and patients with preexisting retinopathy.

\section{Monitoring}

A baseline electrocardiogram should be done to rule out congenital/acquired long QT syndrome and second- or third-degree atrioventricular blocks. Electrolyte imbalances (hypokalemia/hypomagnesemia/hypocalcemia) must be corrected before starting hydroxychloroquine.

\section{Side effects}

Hydroxychloroquine can cause hypoglycemia, ${ }^{[21]}$ QTc prolongation, and torsades de pointes that can lead to fatal ventricular arrhythmia ${ }^{[22]}$ or cardiomyopathy. ${ }^{[23]}$

Is there evidence to support hydroxychloroquine prophylaxis?

An in vitro study showed hydroxychloroquine to be more potent than chloroquine in inhibiting COVID-19 infection. ${ }^{[24]}$ A phase 3 RCT from Columbia University comparing hydroxychloroquine prophylaxis with placebo for household contacts of index cases with an estimated sample size of 1600 is planned. ${ }^{[25]}$ The hydroxychloroquine prophylaxis is debatable given the inadequate evidence to support, potentially fatal side effects due to QTc prolongation, risk of hemolytic anemia in patients with glucose-6-phosphate dehydrogenase deficiency, and a possible shortage of hydroxychloroquine for patients with malaria, rheumatoid arthritis, and systemic lupus erythematosus. ${ }^{[26]}$

\section{Prevention}

\section{Vaccine}

Vaccines are a crucial component for COVID-19 prevention as there is rapid clinical deterioration and no effective treatment. Currently, m-RNA and nucleic acid-based vaccine clinical trials against COVID-19 infection are ongoing. [27]

\section{World Health Organization - Solidarity trial}

This trial randomizes patients with COVID-19 infection to either local standard of care or local standard of care plus one of the four experimental therapies (remdesivir, chloroquine or hydroxychloroquine, lopinavir + ritonavir, lopinavir + ritonavir + interferon beta-1a). Currently, the Canadian arm is recruiting patients for the treatment with lopinavir + ritonavir, and Norwegian arm is recruiting patients for the treatment with remdesivir or hydroxychloroquine.

\section{Conclusion}

Currently, the appropriate prevention, prophylaxis, and treatment of COVID-19 infection are largely unknown. Symptomatic supportive care with active participation in clinical trials is encouraged. We await the results of many ongoing RCTs to guide us in the prevention and management of COVID-19 infection [Tables 2 and 3]. 


\section{Manikandan Dhanushkodi', Padmaj Kulkarni ${ }^{2}$}

${ }^{1}$ Department of Medical Oncology, Cancer Institute (WIA), Chennai, Tamil Nadu, India, ${ }^{2}$ Department of Medical Oncology, Deenanath Mangeshkar Hospital, Pune, Maharashtra, India

Address for correspondence: Dr. Manikandan Dhanushkodi, Cancer Institute (WIA), 38 Sardar Patel Road, Chennai - 600 036, Tamil Nadu, India. E-mail:dmani1982@gmail.com

Submitted: 25 -Apr-2020

Revised: 28-Apr-2020

Accepted: 01-May-2020

Published: 04-Jun-2020

\section{References}

1. Zou L, Ruan F, Huang M, Liang L, Huang H, Hong Z, et al. SARS-CoV-2 viral load in upper respiratory specimens of infected patients. N Engl J Med 2020;382:1177-9.

2. Udugama B, Kadhiresan P, Kozlowski HN, Malekjahani A, Osborne M, Li VYC, et al. Diagnosing COVID-19: The disease and tools for detection. ACS Nano 2020;14:3822-35.

3. COVID-19 Indian Council of Medical Research Government of India. Available from: https://icmr.nic.in/content/covid-19. [Last accessed on 2020 Apr 15].

4. Sanders JM, Monogue ML, Jodlowski TZ, Cutrell JB. Pharmacologic treatments for coronavirus disease 2019 (COVID-19): A review. JAMA 2020;323:1824-36.

5. Grein J, Ohmagari N, Shin D, Diaz G, Asperges E, Castagna A, et al. Compassionate use of remdesivir for patients with severe Covid-19. N Engl J Med 2020 Apr 10;NEJMoa2007016. doi: 10.1056/NEJMoa2007016. Online ahead of print.

6. Cao B, Wang Y, Wen D, Liu W, Wang J, Fan G, et al. A trial of lopinavir-ritonavir in adults hospitalized with severe Covid-19. N Engl J Med 2020;382:1787-99.

7. Gautret P, Lagier JC, Parola P, Hoang VT, Meddeb L, Mailhe M, et al. Hydroxychloroquine and azithromycin as a treatment of COVID-19: Results of an open-label non-randomized clinical trial. Int J Antimicrob Agents 2020 Mar 20;105949. doi: 10.1016/j.ijantimicag.2020.105949. Online ahead of print.

8. Molina JM, Delaugerre C, Le Goff J, Mela-Lima B, Ponscarme D, Goldwirt L, et al. No evidence of rapid antiviral clearance or clinical benefit with the combination of hydroxychloroquine and azithromycin in patients with severe COVID-19 infection. Med Mal Infect 2020;50:384.

9. Moore, N. Chloroquine for COVID-19 Infection. Drug Saf 2020;43:393-4.

10. Wu Y, Wang $\mathrm{T}$, Guo $\mathrm{C}$, Zhang $\mathrm{D}$, Ge X, Huang Z, et al. Plasminogen improves lung lesions and hypoxemia in patients with COVID-19. QJM 2020 Apr 10;hcaa121. doi: 10.1093/ qjmed/hcaa121. Online ahead of print.

11. Marano G, Vaglio S, Pupella S, Facco G, Catalano L, Liumbruno $\mathrm{GM}$, et al. Convalescent plasma: New evidence for an old therapeutic tool? Blood Trans 2016;14:152-7.

12. Duan K, Liu B, Li C, Zhang H, Yu T, Qu J, et al. Effectiveness of convalescent plasma therapy in severe COVID-19 patients. Proc Natl Acad Sci U S A 2020;117:9490-6.

13. Shen C, Wang Z, Zhao F, Yang Y, Li J, Yuan J, et al. Treatment of 5 critically Ill patients with COVID-19 with convalescent plasma. JAMA 2020;323:1582-9.

14. Leo L. ICMR Seeks Participation for Trial of Plasma Therapy for Covid-19 Treatment; 2020. Available from: https://www. livemint.com/news/india/icmr-seeks-participation-for-trial-of-plas ma-therapy-for-covid-19-treatment-11586784202205.html. [Last accessed on 2020 Apr 15].

15. Luo P, Liu Y, Qiu L, Liu X, Liu D, Li J. Tocilizumab treatment in COVID-19: A single center experience. J Med Virol 2020 Apr 6. doi: 10.1002/jmv.25801. Online ahead of print.

16. Wu C, Chen X, Cai Y, Xia J, Zhou X, Xu S, et al. Risk factors associated with acute respiratory distress syndrome and death in patients with coronavirus disease 2019 pneumonia in Wuhan, China. JAMA Intern Med 2020 Mar 13;e200994. doi: 10.1001/ jamainternmed.2020.0994. Online ahead of print.

17. Shang L, Zhao J, Hu Y, Du R, Cao B. On the use of corticosteroids for 2019-nCoV pneumonia. Lancet 2020;395:683-4.

18. Tang N, Bai H, Chen X, Gong J, Li D, Sun Z. Anticoagulant treatment is associated with decreased mortality in severe coronavirus disease 2019 patients with coagulopathy. J Thromb Haemost 2020;18:1094-9.

19. Alhazzani W, Møller MH, Arabi YM, Loeb M, Gong MN, Fan E, et al. Surviving sepsis campaign: Guidelines on the management of critically ill adults with coronavirus disease 2019 (COVID-19). Intensive Care Med 2020;46:854-87.

20. Available from: http://HCQ_Recommendation_22March_final_ MM_V2.pdf. [Last accessed on 2020 Apr 15].

21. Cansu DÜ, Korkmaz C. Hypoglycaemia induced by hydroxychloroquine in a non-diabetic patient treated for RA. Rheumatology (Oxford) 2008;47:378-9.

22. Chen CY, Wang FL, Lin CC. Chronic hydroxychloroquine use associated with QT prolongation and refractory ventricular arrhythmia. Clin Toxicol (Phila) 2006;44:173-5.

23. Joyce E, Fabre A, Mahon N. Hydroxychloroquine cardiotoxicity presenting as a rapidly evolving biventricular cardiomyopathy: Key diagnostic features and literature review. Eur Heart J Acute Cardiovasc Care 2013;2:77-83.

24. Yao X, Ye F, Zhang $\mathrm{M}$, Cui $\mathrm{C}$, Huang $\mathrm{B}$, Niu $\mathrm{P}$, et al. In vitro antiviral activity and projection of optimized dosing design of hydroxychloroquine for the treatment of severe acute respiratory syndrome coronavirus 2 (SARS-CoV-2). Clin Infect Dis 2020 Mar 9; ciaa237. doi: 10.1093/cid/ciaa237. Online ahead of print.

25. Hydroxychloroquine Post Exposure Prophylaxis for Coronavirus Disease (COVID-19) - Full Text View - ClinicalTrials. Available from: https://clinicaltrials.gov/ct2/show/NCT04318444. [Last accessed on 2020 Apr 15].

26. Rathi S, Ish P, Kalantri A, Kalantri S. Hydroxychloroquine prophylaxis for COVID-19 contacts in India. Lancet Infect Dis 2020 Apr 17;S1473-3099(20)30313-3. doi: 10.1016/S14733099(20)30313-3. Online ahead of print.

27. Lurie N, Saville M, Hatchett R, Halton J. Developing covid-19 vaccines at pandemic speed. New England J Med 2020;382:1969-73.

This is an open access journal, and articles are distributed under the terms of the Creative Commons Attribution-NonCommercial-ShareAlike 4.0 License, which allows others to remix, tweak, and build upon the work non-commercially, as long as appropriate credit is given and the new creations are licensed under the identical terms.

\begin{tabular}{|l|l|}
\hline \multicolumn{2}{|c|}{ Access this article online } \\
\hline Quick Response Code: & Website: \\
\hline
\end{tabular}

How to cite this article: Dhanushkodi M, Kulkarni P. COVID-19 management: What we need to know? Indian J Med Paediatr Oncol 2020;41:441-5. 